\title{
Review on Technical Efficiency of maize Production in Ethiopia
}

\author{
Tolesa Tesema Edosa
}

\begin{abstract}
The economy of Ethiopia is based on agriculture. Maize (Zea mays) is one of the most important food crops produced by smallholder farmers in Ethiopia and accounted for $28 \%$ of total grain production during the 2011/12 Meher season. However, low production and productivity characterizes Ethiopian maize production. The low levels of maize productivity may be the result of technical inefficiencies. Therefore the objective of this review is to review level of technical efficiency and assess the source of technical efficiency in Ethiopia. The review suggested the presence of considerable levels of technical inefficiency in maize productivity. From the empirical estimation, important variables affecting the technical efficiency were found Agro-ecology, oxen holding, farm size and use of high yielding maize varieties, sex, age, membership to cooperatives, training, distance to extension agents and main market, credit, family size, livestock and off-farm income. The most important factor to promote production efficiency is probably access to credit.
\end{abstract}

DOI: $10.7176 / \mathrm{FSQM} / 84-03$

\section{INTRODUCTION}

\subsection{BACKGROUND AND JUSTIFICATION}

The economy of Ethiopia is based on agriculture, which accounts for $46.3 \%$ of gross domestic product (GDP), $60 \%$ of exports, and $80 \%$ of total employment (FAO,2014).Ethiopian agriculture is predominantly rain fed, smallholder farming on land areas averaging less than two hectares (MoARD, 2010).Low productivity is attributed to limited access to modern inputs such as chemical fertilizer, improved seeds, and limited access for finance, poor access to irrigation systems and agricultural markets, poor land management practices that resulted in severe land degradation Despite such drawbacks, the agricultural sector performed remarkably since 1996/97 and registered a growth rate of about 10\% per an-num until 2003/04 (MOARD, 2010). However, between 2003/04 and 2011/12 the growth rate slowed to $9.3 \%$, as the growth rate for the year 2011/12 dropped to $4.9 \%$ (MOFED, 2013).

Thus, increasing crop production enhances agricultural output in particular and the gross domestic product in general, and is essential to improve the income and living conditions of the majority of citizens (FAO, 2014). Increment of productivity and production of agricultural sector by using improved technologies will be high if it is coupled with the improvement of the existing level of inefficiency of farmers (Asefa S, 2011)

Maize (Zea mays) is one of the most important food crops produced by smallholder farmers in Ethiopia and accounted for $28 \%$ of total grain production during the 2011/12 Meher season2 (CSA, 2012). More than nine million smallholder farmers are involved in maize cultivation on about two million hectares of land during the 2011/12 Meher season (CSA, 2012). Maize area and yields in Ethiopia have doubled since the early 1990s. Despite the significant changes, there are unexploited opportunities for further increasing maize productivity and production in Ethiopia(Tsedeke Abate,etal,2015)

However, low production and productivity characterizes Ethiopian maize production (World Bank, 2006; MoARD, 2009). There is a growing food shortage in Ethiopia due to the poor performance of the agricultural sector (Alene and Hassan, 2003).

Agricultural Development-Led Industrialization (ADLI) is a long term strategy in which, at the early stages of development, the agricultural sector is expected to play a leading role in the growth of the economy (MoFED, 2002 , p.38).In response to the agricultural development strategy, the adoption and use of chemical fertilizers, improved seeds and other related inputs increased substantially in Ethiopia, particularly in maize production. However, maize productivity has not shown substantial improvement (Arega and Zeller, 2005).One of the reason for low productivity could lies in the smallholders' technical inefficiency (Gebreselassie, 2006).

A Plan for Accelerated and Sustainable Development to End Poverty (PASDEP) was a five year plan (2005/06-2009/10) which put due emphasis on the commercialization of agriculture and integrating farmers with markets (MoFED, 2006, p. 47). In addition, during the period of PASDEP, the supply of agricultural inputs such as fertilizers, improved seeds and pesticides was expected to increase substantially (MoFED, 2006, p. 57).Five years later, PASDEP was replaced by the Growth and Transformation plan (GTP). The main focus of the GTP related to agricultural and rural development is to increase the capacity and extensive use of labour, enhance utilization of land, link specialization with diversification and strengthen agricultural marketing systems (MoFED, 2010, p. 45).

Improvement of agricultural productivity provides an important solution in addressing the problems of food insecurity and poverty, and enhancing the development of agriculture in Ethiopia. Consequently, attempts are being channeled in ways by which increased agricultural productivity can be achieved through promoting the use of improved agricultural technologies and improving the efficiency of production of cereal crops in Ethiopia 
(Sinafikeh et al., 2010; Yu and Nin-Pratt, 2014). Cereals are the major staple food crops both in terms of area planted and volume of production obtained. For example, in 2013/14 main crop season, cereals were cultivated on 9.9 million hectares of land producing 22 million tons of food grains. This represented $79.38 \%$ and $85.81 \%$ of the total area and production of food grains in the country, respectively (CSA, 2014a).

Maize is the most important cereal crops in terms of availability and utilization of improved agricultural technologies such as fertilizer, improved seeds, pesticides, herbicides and better farm management practices than other cereal crops after 2002 of SDPRP and this has improved among other things the production and productivity of maize in the country over the last years (Sinafikeh et al., 2010; CSA, 2014b).

\subsection{Statement of problem}

The agricultural sector is the backbone of the Ethiopian economy. It is the leading sector that contributes to the Gross Domestic Product of the country. However, as farming in Ethiopia is precarious and usually at the mercy of nature, it is invariably an arduous struggle for the smallholders to make ends meet (CSA, 2009, p. 3).

Maize is the most important staple in terms of calorie intake in rural Ethiopia. The 2004/5 national survey of consumption expenditure indicated that maize accounted for $16.7 \%$ of the national calorie intake followed by sorghum (14.1\%) and wheat (12.6\%) among the major cereals (Berhane et al. 2011). Compared to the 1960s the share of maize consumption among cereals more than doubled to nearly $30 \%$ in the $2000 \mathrm{~s}$, whereas the share of teff, a cereal that occupies the largest area of all crops in Ethiopia, declined from more than $30 \%$ to about $18 \%$ during the same period (Demeke 2012 ).

Food production even under improved technology in developing countries involves substantial inefficiencies due to farmers' high unfamiliarity with new technology coupled with poor extension, education, credit, and input supply systems. This is even more pronounced in Ethiopia where the gap between the demand for and supply of extension services is growing and consequently the services are of poor quality and have very low coverage.(Alene et.,al(2005). Low agricultural productivity and an increasing population contribute to increased food insecurity and poverty in Sub-Saharan Africa in general and in Ethiopia in particular (Geta et al., 2010). In order to improve maize production and productivity, an efficient use of production inputs should be adopted by smallholder farmers. An understanding of the relationships between productivity, efficiency, policy indicators and farm-specific practices would provide policy makers with information to design programs that can contribute to increasing food production potential among smallholder farmers (Msuya et al. 2008). Therefore if farmers are producing to supply the surplus to the market after feeding themselves with reducing land per capita due to population growth, they need to adopt new farming practices and increase their efficiency (Jema Haji, 2008). It is possible to improve the current productivity by increasing technical efficiency. The current level of production efficiency can be improved by ownership of oxen, access to extension services, access to credit, use of improved seed varieties and by promoting soil and land conservation practices and by promoting small- scale irrigation schemes (sorsie et., al 2015). Therefore This review aims at assessing the levels of technical efficiency and identify the source that influence levels of technical efficiency in Ethiopia.

\subsection{Objectives of the review}

\subsubsection{General objective}

The general objective of the review is to review technical efficiency of smallholder maize production in Ethiopia.

\subsubsection{Specific objective}

The specific objectives of the reviews are:

1. To review the level of technical efficiency of maize producing smallholder farmers in Ethiopia

2. To review the principal factors that causes efficiency differentials in maize production in Ethiopia.

\section{LITERATURE REVIEW}

\subsection{Theoretical literature review}

\subsubsection{Review on the Concept of Production Efficiency}

Production in economics generally refers to the transformation of inputs into outputs (Thomas and Maurice, 2013). The inputs are basically the raw materials or any other resources that are combined to give an output. The output refers to the end product or final production of the combination of resources.

Production of different goods and services can be analyzed using short and long-run concept. The central feature of short-run production analysis is the law of diminishing marginal returns, which results in the short run when larger amounts of a Variable input, like labour, are added to a fixed input, like capital (Thomas and Maurice, 2013)

Productivity and efficiency are two different concepts except under the assumption of constant return to scale. According to Fried et al. (2008), productivity is a ratio of production output to what is required to produce it (inputs). The measure of productivity is defined as a total output per one unit of total input. This measure is easily 
calculated if the farmer uses a single input to produce a single output. However, when multiple inputs are used to produce several outputs, the output in the numerator and the inputs in the denominator have to be combined in some sensible economic fashion so that productivity remains the ratio of two scalars (Coelli et al., 2002). Efficiency is a commonly used term in economicsIt is measured by comparing the observed output against the feasible (frontier) output (Fried et al., 2008).

By many scholars productivity and efficiency are used interchangeably and both are considered as the measure of performance of a given firm. However, these two interrelated terms are not precisely the same (Coelli et al., 1998). In simple terms, productivity is the quantity of a given output of a firm per unit of input. According to Farrell (1957), efficiency is measured by comparing the actually attained or real value of the objective function against what is attainable at the frontier. A producer is efficient if his/her goals are achieved, and inefficient if he/she falls below his/her goal. It is a relation between end and means. Efficiency measures the amount to which the ends and means available to the unit and to the society are matched. Thus, technical inefficiency is costly; both to the producing unit under investigation and the society at large (Fare et al., 1985).

Farrell (1957) proposed a measure of the efficiency of a firm that consists of two types: Technical and allocative efficiency. These two measures are then combined to provide a measure of total economic efficiency.

Conceptually, technical efficiency refers to the ability of a firm to produce as much output as possible with a specified level of inputs, given the existing level of technology. Technical efficiency concerns the method through which physical quantities of inputs are changed into physical quantities of output. Producers are said to be technically efficient if they achieve maximum feasible output from inputs (Coelli et al., 1998). Technical inefficiency can be defined as the quantity by which a firm lies below its production frontier or profit frontier. Once the frontier is known, simply comparing the efficiency level of the firm relative to the frontier can help to know inefficiency of any specific firm (Farrell, 1957).

The firm is more inefficient, when it is more distant far (gap) from the frontier. Therefore, the frontier must be constructed first from the production, profit and cost available observations, to determine the efficiency level of the firm (Forsund et al., 1980). On the other hand, allocative efficiency is the ability of a firm to use the inputs in optimal proportions, given their respective prices. A firm is allocatively efficient if production occurs in a subset of economic boundary of the production possibilities set which satisfies the firm's objectives. The location of this sub-set is determined by the prices faced and the goal pursued by the firms. Economic efficiency combines both technical and allocative efficiencies. It refers to the proper choice of inputs and products combination according to their price relation or the ability of the firm to maximize profit by equating marginal revenue product of inputs to their respective marginal costs. Farrell(1957) illustrated these three measures of efficiency using figure 1 below, which involves two inputs (X1 and X2 ) to produce a single output (Y), under the assumption of constant returns to scale. The constant returns-to-scale assumption allows representing the technology using a unit isoquant. Furthermore, Farrell also discussed the extension of his method so as to accommodate more than two inputs. Knowledge of the unit isoquant of fully efficient firm, represented by SS' in Figure 1, permits the measurement of technical efficiency. If a given firm uses quantities of inputs, defined by the point $P$, to produce a unit of output, the technical inefficiency of that firm could be represented by the distance QP, which is the amount by which all inputs could be proportionally reduced without a reduction in output. This is usually expressed in percentage terms of the ratio $\frac{\mathrm{QP}}{\mathrm{OP}}$ which represents the percentage by which all inputs need to be reduced to achieve technically efficient production. The technical efficiency (TE) of a firm is most commonly measured by the ratio

$$
\frac{O Q}{O P}=1-Q P / O P
$$

$\mathrm{TE}_{\mathrm{i}}$ takes values between zero and one, and hence provides an indicator of the degree of technical inefficiency of the firm. A value of one indicates the firm is fully technically efficient. For example, the point $\mathrm{Q}$ is technically efficient because it lies on the efficient isoquant

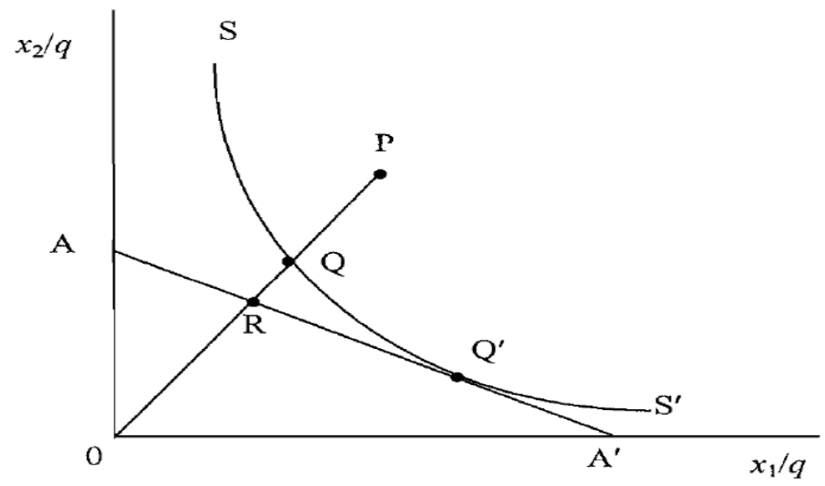

Fig1 technical and allocative efficiency Source: Farrell (1957) 
If the input price ratio, represented by the slope of isocost line $\mathrm{AA}^{\prime}$, is also known, allocative efficiency (AE) of the firm operating at point $\mathrm{P}$ could be measured as the ratio:

$$
A E=\frac{O R}{O Q}
$$

Since the distance RQ represents the reduction in production costs that would occur if production were to occur at the allocatively (and technically) efficient point Q', instead of at the technically efficient, but allocatively inefficient, point Q. This indicates the irrespective of the slope of these two parallel lines (determined by the input price ratio) the ratio $\mathrm{RQ} / \mathrm{OQ}$ represents the proportional reduction in costs of production associated with movement from Q to Q' (Farrell, 1957).

The total economic efficiency (EE) is defined to be the ratio:

$$
E E i=\frac{O R}{O P}
$$

These efficiency measures assume that the production function is known. However, in practice, the isoquant is never known. Hence, these isoquants that represent the efficient points must be estimated from sample data. But the question here is how to estimate production frontiers that represent efficient points of production.

The above input-oriented technical efficiency measures address the question: "By how much can input quantities be proportionally reduced without changing the output quantities produced?". One could alternatively ask the question: "By how much can the output be proportionally expanded without altering the inputs quantities used?"This is all output-oriented measures as opposed to the input-oriented measure discussed above. One can consider output-oriented measures further by considering the case where production involves two outputs ( $\mathrm{Y}_{1}$ and $\mathrm{Y}_{2}$ ) and a single input $(\mathrm{X})$. If we hold the input quantity fixed at particular level, we can represent the technology by a unit production possibility curve in two dimensions (Coelli et al., 1998).

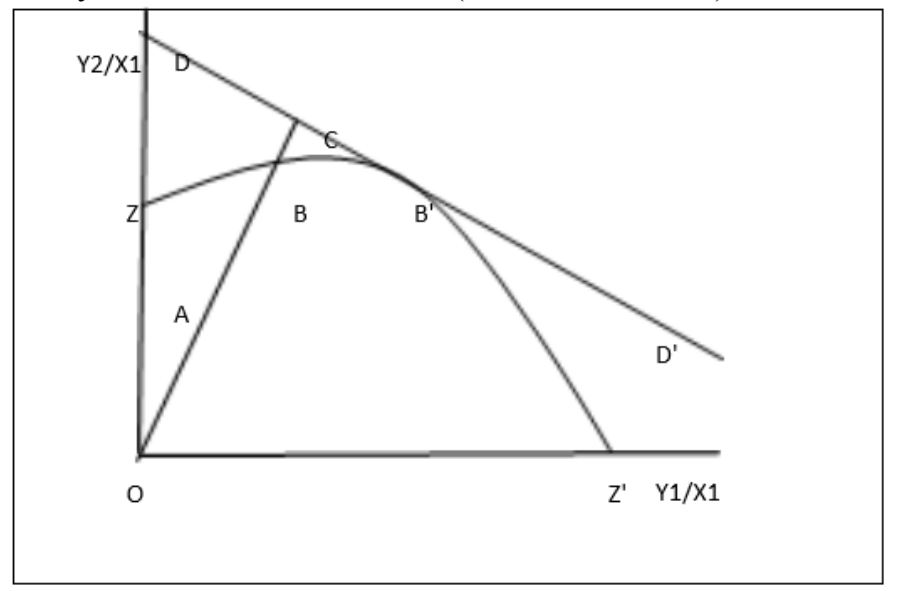

Fig. 2 Technical and Allocative Efficiencies from an output orientation Source: Farrell (1957)

The line $Z Z^{\prime}$ is the unit production possibility curve and point A corresponds to an inefficient farm. The inefficient point, A, lies below the curve ZZ', which represents the upper bound of production possibilities (Coelli et al., 1998). The Farrell's output-oriented efficiency measure is defined as follows. In Figure 2, above the distance $\mathrm{AB}$ represents technical inefficiency (the technical inefficiency is the ratio, $\mathrm{AB} / \mathrm{OB}$ ). That is, the amount by which outputs could be increased without requiring extra inputs. Hence a measure of output-oriented technical efficiency is the ratio

$$
T E=\frac{O A}{O B}
$$

This has a revenue increasing interpretation (similar to the cost reducing interpretation of allocative inefficiency in the input-oriented case). Furthermore, we can define overall economic efficiency as the product of these two measures.

$$
E E A=\frac{O A}{O C}=\left(\frac{O B}{O C}\right) *\left(\frac{O B}{O C}\right)=T E A * A E A
$$

Thus in Figure 2, if DD' has a slope equal to the ratio of price of outpus, B' is the optimal method of production, for this point represents 100 percent technical and allocative efficiencies (Coelli et al., 1998).

\subsubsection{Review on Models of Measuring Production Efficiency}

Lovell (1993) provides an excellent introduction to this topic. The two principal methods that have been used are data envelopment analysis (DEA) and parametric models, which involve mathematical programming and econometric methods, respectively. The parametric frontier model may further be categorized into deterministic and stochastic frontier models. The main feature of the deterministic frontier is that it assumes all firms share a 
common family of production, cost and profit frontiers and all variations in the firm's performance are attributed to variations in the firm's efficiency. On the other hands, the non-parametric deterministic frontier is based upon Farrell's original approach of piecewise linear convex isoquant such that no observed points lie to the left or below it (Farrell, 1957). This work has been extended by Charnes et al. (1978) and was called Data Envelopment Analysis (DEA). The frontier methodology has been widely used in production analysis mainly due to its consistency with the text book definition of a production, profit or cost functions (i.e. with the notion of maximization or minimization). This popularity is evidenced by the proliferation of methodological and empirical frontier studies over the last two decades. Despite these wide arrays of applied work, the extent that empirical measures of efficiency are sensitive to the choice of methodology remains a matter of controversy (Thiam et al., 2001). The frontier methodologies are basically measurements of technical efficiency that shifts the average response functions to the maximum output or to the efficient firm (Coelli et al, 1998). In a production frontier, a technically efficient farmer is always located on the frontier while the inefficient farmer at the anterior (Coelli et al., 2002). One way of reducing the cost of production in a farm is to increase farm output by increasing technical efficiency (Fried et al., 2008).

\subsubsection{Review on non-parametric frontier models}

One of the methods of efficiency measurements is the non-parametric method. The DEA frontier is both nonparametric and non-stochastic since it does not impose any a priori parametric restrictions on the underlying frontier technology (because it does not necessitate any functional form to be specified) and doesn't require any distributional assumption for the technical inefficiency term. Therefore, the model avoids the imposition of unwarranted structures on both the frontier technology and the inefficiency component that might create distortion in the measurement of efficiency (Fare et al., 1985) Charnes et al. (1978) proposed a model which had an inputoriented constant return to scale (CRS) model of DEA

CRS assumption is only appropriate when all firms are operating at an optimal scale. In case of different constraints, may cause a firm to be not operating at optimal scale. The use of the CRS specification when not all firms are operating at the optimal scale, the results in measure of TE which are confound by scale efficiency (SE). The shortcoming of scale efficiency is that the value does not indicate whether the firm is operating in an area of increasing or decreasing returns to scale (Coelli et al., 1998).

The advantage of non-parametric approach is that no functional form is imposed on the data, while its disadvantage lies in its assumption of constant reruns to scale and susceptibility of the frontiers to extreme observations (Forsund et al., 1980). Particularly, the main criticism of DEA is that it assumes all deviations from the frontier are due to inefficiency and because of this, non-parametric frontier methodology may overstate inefficiencies and hence outliers may have profound effect on the magnitude of inefficiency (Licwelgn and Williams, 1996). In addition, in DEA no account is taken of the possible influence of measurement errors and other noise upon the frontier. All deviations from the frontier are assumed to be the result of technically inefficiency. An alternative method or approach to the solution of the noise problem has, however, been widely adopted. This is the method known as the stochastic frontier approach, which is thoroughly reviewed below.

\subsubsection{Review on Parametric frontier models}

The parametric model of efficiency analysis uses econometric techniques and can be classified into deterministic and stochastic frontier. The basic difference between the two types of models is the following. The deterministic model assumes that any deviation from the frontier is due to inefficiency, while the stochastic approach allows for the statistical noise.

\subsubsection{Deterministic frontier model}

The deterministic frontier model uses econometric techniques to estimate the parameters of the pre-specified functional forms. Aigner and Chu (1968) considered the estimation of the parametric frontier production function of Cobb-Douglas form. According to them the model is defined as follows.

$$
\ln Y i=x i \beta-u i \quad, i=1,2, \ldots . N \text {, }
$$

Where, $\ln \left(\mathrm{Y}_{\mathrm{i}}\right)=$ the natural logarithm of the (scalar) output for the $\mathrm{i}^{\text {th }}$ firm;

$\mathrm{x}_{\mathrm{i}}=\mathrm{a}(\mathrm{k}+1)$ a row vector, whose first element is " 1 " and the remaining $\mathrm{x}$ elements are the logarithms

of the $\mathrm{k}$ input quantities used by the $\mathrm{i}^{\text {th }}$ firm;

$\beta=\left(\beta_{0}, \beta_{1}, \ldots, \beta_{\mathrm{k}}\right)$ is a $(\mathrm{k}+1)$ column vector of unknown parameters to be estimated.

$u_{i}=$ is a non-negative random variable associated with technical inefficiency.

Therefore, the ratio of the observed output for the $\mathrm{i}^{\text {th }}$ firm, relative to the potential output, defined by the frontier function, given the input vector, $\mathrm{x}_{\mathrm{i}}$, is used to define the technical efficiency of the $\mathrm{i}^{\text {th }}$ firm.

$$
T E_{i}=\frac{Y_{i}}{\exp \left(X_{i} \beta+v_{i}\right)}=\exp \left(-\mu_{i}\right)=\frac{Y_{i}}{Y^{*}}
$$

The criticisms of the above deterministic frontier model is that no account is taken of the possible influences of measurement errors and other noise upon the frontier (Coelli et al.,1998).

Efficiency measures for all deterministic frontiers are then calculated relative to the common family of frontier. Hence the estimated frontier is the "best practice" frontier of the sample and not the "absolute" frontier 
(Forsund et al., 1980). Thus, the deterministic approach assumes all deviations from the frontier to be due to inefficiencies and it ignores the possibility that a firm's performance may also be affected by factors entirely outside the control of the producers. Thus, the deterministic method will sum-up the effect of exogenous shocks together with measurement error and inefficiency. Timmer (1971) developed the probabilistic frontier as a solution to the outliers in the above deterministic estimation approaches. Timmer imposed a Cobb-Douglas structure and estimated the parameter using linear programming by discarding the outliers until the parameter value stabilizes. The deterministic model considers that any deviation from the frontier is due to inefficiency. Hence when there is high random error on the data, the inefficiency estimates will be exaggerated as compared to other models, which take into account random errors.

Thiam et al., (2001) found that models using stochastic frontier did not generate significantly different technical efficiency indicators than deterministic models. In their study they indicated also that, this finding contradicts with their a priori expectations that inefficiency scores would be high for deterministic models than stochastic frontier. The reason could be that the proportion of deviation due to noise might be less than the deviations due to inefficiency.

In most of empirical studies of technical efficiency in agriculture stochastic frontier model is used due to the very nature of agricultural output that is affected by natural hazards, climatic conditions and measurement errors that could be attribute to the existence of noise in the data. Therefore, most recent studies on technical efficiencies in agriculture have used stochastic frontier model to account for random noise (Coelli et al., 1998).

\subsection{Stochastic frontier model}

The stochastic frontier production function was independently proposed by (Aigner et al., 1977; Meeusen and Von den Broeck, 1977). The original specification involved a production function specified for cross-sectional data which had an error term with two components, one to account for random effects and another to account for technical inefficiency. This model can be expressed in the following form:

$$
\ln Y=x i \beta+v i-u i
$$

Where, $\mathrm{V}_{\mathrm{i}}=$ random error term of the model, and other variables are defined as in equation. The maximum likelihood estimates of the parameters of the frontier model are estimated, the variance parameters are expressed in terms of the parameterization

$$
\begin{gathered}
\delta s^{2}=\delta v^{2}+\delta^{2}, \\
\gamma=\delta^{2} / \delta s^{2}=\delta^{2} / \delta v^{2}+\delta^{2}
\end{gathered}
$$

Where, the $\gamma$ parameter has a value between 0 and 1. A value of $\gamma$ of zero indicates that the deviations from the frontier are due entirely to noise, while a value of one would indicate that all deviations are due to technical inefficiency.

$\delta^{2}$ - is the variance parameter that denotes deviation from the frontier due to inefficiency;

$\delta v^{2}$ - is the variance parameter that denotes deviation from the frontier due to noise.

$\delta s^{2}$ - is the variance parameter that denotes the total deviation from the frontier.

Battese and Coelli (1988) pointed out that in the prediction of farmers level technical efficiencies which the best predictor of $\operatorname{Exp}(\mathrm{Ui})$ is obtained by: The explanatory variables used for the inefficiency effects in the stochastic frontier model are defined as follows:

The best prediction of firm level efficiency, $\exp \left(-\mathrm{U}_{\mathrm{i}}\right)$, can be obtained by:

$$
E\left[\exp \left(\frac{-u i}{e i}\right]=\frac{1-\left(\delta v+\frac{\gamma e i}{\delta v}\right) \exp \left(y e i+\frac{\delta^{2}}{2}\right)}{1-\emptyset\left(\frac{\gamma e i}{\delta v}\right)}\right.
$$

Where $\delta v=\sqrt{\gamma(1-\gamma) \delta s^{2}}$

$$
e i=\ln (Y i)-X i \beta
$$

$\emptyset$ is the density function of a standard normal random variables

The random error, Vi accounts for measurement error and other factors, such as the effects of weather, strikes, chance, etc., on the value of the output variable, together with the combined effects of unspecified input variables in the production function.

Aigner et al. (1977) assumed that the Vi were independently and identically distributed (i.i.d) normal random variables with mean zero and constant variance, $\delta^{2}$, independent of the $u i$ that were assumed to be independent and identically distributed exponential or half-normal random variables. The model, defined by Equation 13, is called the stochastic frontier production function because the output values are bounded above by the stochastic (random) variable, $\exp \left(x i \beta+V i\right.$. The random error, $\mathrm{Vi}_{\mathrm{i}}$, can be positive or negative and so the stochastic frontier outputs vary about the deterministic part of the frontier model (Coelli et al., 1998) 


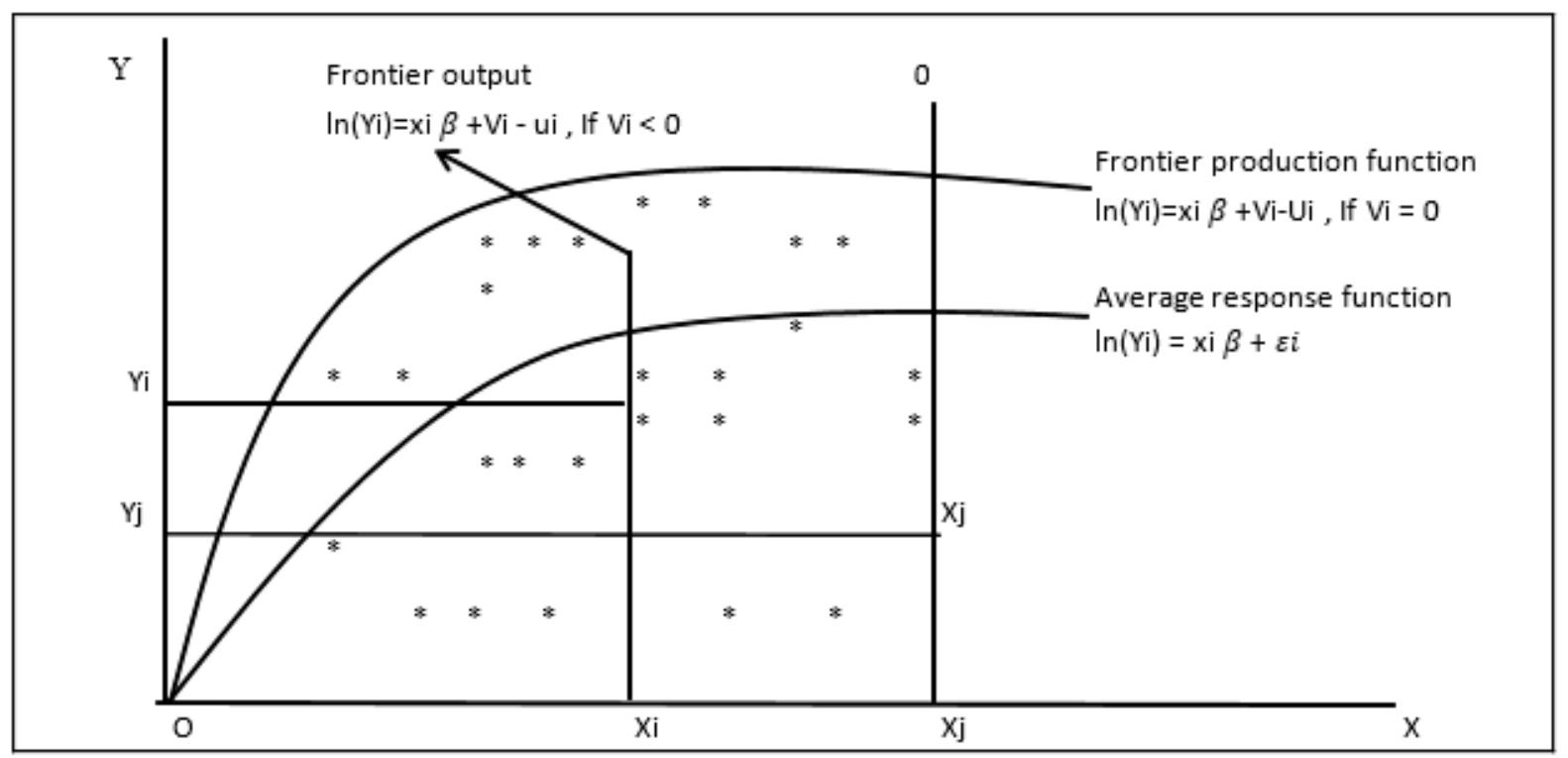

Fig. 3 The stochastic frontier production function

Source: Coelli et al. (1998).

Based on the Figure 3, the deterministic component of the frontier model, $\ln Y i=x i \beta-U i$ is drawn assuming diminishing returns to scale applies. The observed inputs and outputs for different firms are represented by dots on the graph. The values of the frontier outputs $\mathrm{Yi}=\ln Y i=x i \beta-U i \pm V i$ is marked by above and below the deterministic frontier production function depending on the value of Vi. The stochastic frontier outputs Yi are not observed because the random errors, $\mathrm{Vi}$, are not observable. The overage response function is estimated using OLS estimator assuming that firms are efficient, which is represented by $\ln Y=x \beta+\varepsilon$ (Coelli et al., 1998).

The symmetric component (Vi) permits random variation of the frontier across firms (measurement error, other statistical noise and random shocks outside the control of the firms) and one-sided component (Ui) that captures the effect of inefficiency relative to the stochastic frontier. The stochastic frontier is also called composed error model, hence the error term is composed of two independent elements. The economic concepts behind the specification of the error term into two components are that the production process is subject to two economically distinguishable random disturbances with different characteristics. $v$ i reflects the fact that each firms output must lie on or bellow its frontier $[f(X i, \beta+V i]$. Any such deviation is the result of factors outside the firm's control, such as technical efficiency. But the frontier itself can vary randomly across firms the frontier is stochastic, with random disturbance $V i \leq$ or $\geq 0$ being the result of favorable as well as unfavorable external events (Aigner et al., 1977).

\subsubsection{Review on Cobb-Douglas Production theory}

The theory explains the factors of production, resources, or inputs are what are used in the production process to produce output that is, finished goods and services. The amounts of the various inputs used determine the quantity of output according to a relationship called the "production function". There are three basic resources or factors of production; land, labor, and capital. These factors are also frequentlylabeled "producer goods" to distinguish them from the goods or services purchased by consumers, which are frequently labeled "consumer goods." All three of these are required in combination at a time to produce a commodity. The essence of a firm is to buy inputs, convert them to outputs, and sell these outputs to consumers and the firm owners seek to improve their positions by producing goods and service either those they consider most important for themselves or those that can be sold to command the goods they consider most important (Thomas and Maurice, 2013).

Cobb-Douglas production function is a particular functional form of the production function, widely used to represent the technological relationship between the amounts of two or more inputs, particularly physical capital and labour, and the amount of output that can be produced by those inputs. The term has a more restricted meaning, requiring that the function display constant returns to scale in which case $\beta=1-\alpha$ In its most standard form for production of a single good

with two factors, the function is $Y=A L^{\beta} K^{\alpha}$ whereas;

- $\mathrm{Y}=$ total production (the real value of all goods produced in a year)

- $\quad L=$ labour input (the total number of person-hours worked in a year)

- $\mathrm{K}=$ capital input (the real value of all machinery, equipment, and buildings)

- $\mathrm{A}=$ total factor productivity

$\alpha$ and $\beta$ are the output elasticities of capital and labour, respectively. These values are constants determined by 
available technology $\alpha+\beta=1$, the production function has constant returns to scale, meaning that doubling the usage of capital $\mathrm{K}$ and labour $\mathrm{L}$ will also double output $\mathrm{Y}$. If $\alpha+\beta<1$, returns to scale are decreasing, and if $\alpha+$ $\beta>1$, returns to scale are increasing. Assuming perfect competition and $\alpha+\beta=1, \alpha \alpha$ and $\beta$ can be shown to be capital's and labourees shares of output (Maddala, 2002).

\subsection{Empirical Review}

A study undertaken in southern Ethiopia with the objective of assessing productivity and technical efficiency of smallholder farmers, based on the data collected from 385 randomly selected farmers in Wolaita and Gamo Gofa zones of Southern Nations, Nationalities and Peoples Region (SNNPR) of Ethiopia, indicated that technical efficiency range between $1 \%-100 \%$. The result assess human labor ,chemical fertilizer,availability of oxen,plating method, use of hybrid maize has a significant and positive effect on maize production. The results of DEA model indicate that the average technical efficiency was found to be about 0.40 . This indicates that if the average farmer in the sample was to achieve the technical efficiency level of its most efficient counterpart, then the average farmer could realize 60 percent cost savings. This indicates that there was a substantial amount of technical inefficiency in maize production. Important factors that significantly affected the technical efficiency were agro-ecology, oxen holding, farm size and use of high yielding maize varieties. (Geta et al., 2013)

According to Sorsie et., al (2015) estimated technical efficiency scores range from 3 to $96 \%$ with an average technical efficiency of $77 \%$. that there is a considerable level of technical inefficiency among the maize farmers that contributed to lowered productivity Results for the technical inefficiency model indicate that efficient farmers are older males with larger households who plant improved seed varieties, received extension services, irrigate the crop and perform soil protection practices. access to off- farm income will increase technical inefficiency. The most important factor to promote production efficiency is probably access to credit. The estimated mean technical efficiency score for the sample is $77 \%$ indicating that on average only $77 \%$ of potential output was achieved using the farmer's production inputs and available resources. indicated that it is possible to improve the current productivity by increasing technical efficiency

Kitila, G. M., \& Alemu, B. A. (2014) examine the level of technical efficiency of smallholder maize producers and identify its determinants in Horo Guduru Wollega zone of Oromia Regional State, Ethiopia. A Cobb-Douglass stochastic production function model was used for the analysis.they assess that the effect of land input, Seed and DAP chemical fertilizer were found to be significant. The parameter estimate for labour,and number of oxen used turned out to be insignificant. Insignificance of the estimated coefficients for labour and oxen which imply that use of these inputs has no significant effect on productivity of maize. socio-economic factors influencing farmers' technical efficiency and maize output positively are:age,education ,extension, off farm activity, Fragmentation.while Age square and total land holding affect technical efeeciency negatively. The results show that maize producers in the study area are technically inefficient and The average estimated technical efficiency for smallholder maize producers ranges from 0.06 to 0.92 average farmer achieves only $66 \%$ efficiency and lies $26 \%$ below the efficiency levels.

Tsegaye and Ernst, investigate if there are potentials of maize productivity gains in Jimma zone, Ethiopia by improving the technical efficiency of the farm households Seka Chekorsa wereda.Livestock ownership, the number of years farmers participated in the agricultural extension program and access to infrastructures had positive effect on the level of TE. However, education had unexpected sign. seed and fertilizer use, which are significant at 5 percent, the remaining variables were found to be statistically insignificant With respect to level of technical efficiency, Around 60 percent of maize producing farmers were operating at a TE level of more than 80 percent. while for some 40 percent of the farm households between 10 to 20 percent and the inefficiency.

According to Nandeeswara and Bealu (2015) analyze productivity and to link the observed technical efficiency levels to farmers' socioeconomic and institutional characteristics in Boricha Woreda, Southern Ethiopia. Most of the inputs on the stochastic frontier were statistically significant Farm size, urea and dap ferfilizer , labor,oxen holding seed. The result showed that technical efficiency indices of sample farmers ranged from 0.15 to 0.94 . The average technical efficiency was found to be 0.72 . This indicates that if the average farmer in the sample were to achieve the technical efficiency level of its most efficient counterpart, then the average farmer could realize 23 percent reduction of wastage in inputs use to produce its most efficient counterpart output. The important variables affecting the technical efficiency negatively were found sex,age, Distance to extension office, distance to market ,family size.while farmsize, livestock ,offfarm income, education,training and membership to cooperative affect positively.

Tefaye, W., \& Beshir, H. (2014) estimate the levels of technical efficiency and identify factors influencing levels of technical efficiency of smallholder maize by using stochastic frontier approach. The results showed that factors such as age, education, labor availability improved seed, training, were negatively related with inefficiency while off farm activity, interaction between education and off-farm income, number of livestock and distance to market were positively related with inefficiency. Although distance to maize plot and land fragmentation have expected sign but did not turn out to be significant. The TE analysis revealed that technical efficiency score of 
sample farms varied from $24 \%$ to $96 \%$, with the mean efficiency level being 86 . The gamma value of 0.73 suggested that $73 \%$ variation in output was due to the differences in technical efficiencies of farm household in Dhidhessa while the remaining $27 \%$ was due to the effect of the disturbance term.

Bekele, A. R. (2013) estimate technical efficiency variation and identify efficiency influencing variables in maize production for smallholder farmer supplemented in Tibila surface water Irrigation scheme found in two districts, namely, Sire and Jeju districts of Arsi zone of Oromia National Regional state. A stochastic frontier production model was used to estimate the levels of technical efficiency for randomly selected 113 irrigated maize producers rangesbeween 5.35\%-98.29 .The result of inefficiency analysis indicates that the average technical efficiency level is about 91.66 percent i.e. most farmers have high scores of technical efficiency. Except age of household head and dependency ratio, other all variables have an inverse relationship with inefficiency score of the farm household. Age of household head, Educational level of household head, livestock holding and access to credit have their expected signs and statistically significant in the study.

\section{Conclusion and recommendation}

\subsection{Conclusion}

The main objective dealt through this review is to assess the level of technical efficiency of maize production and identify sources of technical efficiency in maize production in Ethioipia in Ethiopia.The from empirical empirical funding conclusion can be drawn is that there is a different level of technical inefficiency among the maize farmers that contributed to lowered productivity and important variables affecting the technical efficiency were found to be sex, age, membership to cooperatives, training, distance to extension agents and main market, credit, family size, livestock and off-farm income.

\subsection{Recommendation}

Based on the above review, the followings recommendations are made:

$>$ Expanding rural infrastructure need to be given due attention in order to increase the technical efficiency.

$>$ Improving the managerial skill of the farm households can lead to increase in maize production at household and regional level.

$>$ Attention should be put on the socioeconomic factors that significantly affect technical efficiency of small-scale farmers for increased maize output in the Ethioipia.

$>$ Since maize production is most important food crops produced by smallholder farmers in Ethiopia, intervention that seek to boost maize output would address challenges related to hunger, malnutrition, food insecurity, poor quality of labour, stagnant rural economic growth, unemployment, household income inequalities and the widespread rural household poverty levels.

$>$ Improving oxen holding of farmers by introducing initiatives such as targeted credit, improved animal health service and technologies that enhance the traction power of the existing oxen.

\section{Referance}

Aigner, D., Lovell, C. K., \& Schmidt, P. (1977). Formulation and estimation of stochastic frontier production function models. journal of Econometrics, 6(1), 21-37.

Aigner, D.J.and S.F. Chu, 1968. An estimating the industry production functions. American Economic Review, 58: 826-839.

Alene, A. D., \& Hassan, R. M. 2006. Erratum: The efficiency of traditional and hybrid maize production in Eastern Ethiopia: An extended efficiency decomposition approach. Journal of African Economies, 15(2), i-xxvii.

Alene, A. D., \& Zeller, M. 2005. Technology adoption and farmer efficiency in multiple crops production in eastern Ethiopia: A comparison of parametric and non-parametric distance functions. Agricultural economics review, 6(1), 5 .

Asefa, S. 2011. Analysis of technical efficiency of crop producing smallholder farmers in Tigray, Ethiopia. Munich Personal RePEc Archive, Paper No. 40461.

Battese, G. E., \& Coelli, T. J. 1988. Prediction of firm-level technical efficiencies with a generalized frontier production function and panel data. Journal of econometrics, 38(3), 387-399.

Bekele, A. R. 2013. Technical Efficiency Variation For Smallholder Irrigated Maize Producers: A Case Study of Tibila Surface Water Irrigation Scheme (Doctoral dissertation, Mekelle University).

Berhane, G., Paulos, Z., Tafere, K., \& Tamru, S. 2011. Foodgrain consumption and calorie intake patterns in Ethiopia. IFPRI Ethiopia Strategy Support Program II (ESSP II) Working Paper, 23.

Central Statistical Agency (CSA). 2012. Agricultural Sample Survey Report on Area and Production of Major Food Crops: Private Peasant Holdings. Meher Season. Addis Ababa Ethiopia

Coelli, T. 1995. Estimators and hypothesis tests for a stochastic frontier function: A Monte Carlo analysis. Journal of productivity analysis, 6(3), 247-268

Coelli, T., D.S.P. Rao and G.E. Battese, 1998. An introduction to efficiency effects in stochastic frontier function 
for panel data. Empirical Economics, 20: 325-332.

Coelli, T., Sandura, R. and Colin, T. 2002). Technical, Allocative, Cost and Scale in Bangladesh Rice Production: A Non-parametric Approach. Agricultural Economics, 53, 607-626.

CSA,2014a. Agricultural sample survey 2013/2014 (2006 E.C.): Volume I - Report on area and production of major crops (Private peasant holdings, Meher season). Statistical Bulletin 532. Central Statistical Agency, Addis Ababa, Ethiopia.

Demeke, M,2012. Analysis of incentives and disincentives for maize in Ethiopia.. Technical notes series, MAFAP. Rome: FAO.

Ethiopia's, A. S. P., \& Pif, I. F. ,2010. Federal Democratic Republic Of Ethiopia Ministry Of Agriculture And Rural Development

FAO.2015. The State of Food Insecurity in the World. Meeting the 2015 International Hunger Targets: Taking Stock of Uneven Progress. Rome, Italy.

FAO.2014. Food And Agriculture Organization Ethiopia country programming 2014-2015 .Ethiopia, Addis Ababa, 2014

Fare, R.S. Grosskopf and C.A.K. Lovell, 1985. Technical efficiency of Philippine agriculture. Applied Economics, 17: $205-214$.

Farrell, M. J. 1957. The measurement of productive efficiency. Journal of the Royal Statistical Society. Series A (General), 120(3), 253-290.

Forsund F., Lovell C.A.K., and Schmidt, P.1980. A servey of frontier production functions and of their relationship to efficiency measurement. J. of Economics, 13: 5-25.

Fried, H., Lovell, K. and Schmidt, S. 2008. The Measurements of Productive Efficiency and Productivity Growth. New York: Oxford University Press, USA.

Fried, H., Lovell, K. and Schmidt, S. 2008. The Measurements of Productive Efficiency and Productivity Growth. New York: Oxford University Press, USA

Gebreselassie, S. 2006. Intensification of Smallholder Agriculture in Ethiopia: Options and Scenarios. Paper prepared for the Future Agricultures Consortium Meeting at the Institute of Development Studies. Addis Ababa, Ethiopia, 20-22 March 2006.

Geta, E., Bogale, A., Kassa, B. and Elias, E. 2010. Productivity and Efficiency Analysis of Smallholder Maize Producers in Southern Ethiopia. Journal of Human Ecology, 41(1):67-75.

Geta, E., Bogale, A., Kassa, B., \& Elias, E. 2013. Productivity and efficiency analysis of smallholder maize producers in Southern Ethiopia. Journal of Human Ecology, 41(1), 67-75.

Gstach D.1998. Technical efficiency in Noisy Multi-output Settings. Working Paper, No. 59, Vienna University of Economics, Vienna.

Jema Haji.2008. Economic Efficiency and Marketing Performance of Vegetable Production in the Eastern and Central parts of Ethiopia: Doctoral Thesis Presented to Swedish University of Agricultural Sciences.

Kitila, G. M., \& Alemu, B. A. 2014. Analysis of Technical Efficiency of Small Holder Maize Growing Farmers of Horo Guduru Wollega Zone, Ethiopia: A Stochastic Frontier Approach. Science, Technology and Arts Research Journal, 3(3), 204-212.

Llewelyn R.V and Williams, J.R.1996. Nonparametric analysis of technical, pure technical and scale efficiencies for food production in East Java, Indonesia. J. of Agricultural Economics, 15: 113-126.

Lovell. C. A. K.1993. Production Frontier and Productive Efficiency, in H. O. Fried, C. A. K. Lovell and S.S. Schmidt (eds): The Measurement of Productive Efficiency. Oxford University Press, New York, 3-67p.

Maddala, G.S. 2002. Introduction to Econometrics. England: John Wiley and Sons, Lt. 3rd Edition, 379 - 380.

Meeuse and J.Van Den Broeck.1977. Efficiency estimation from Cobb-Douglas production functions with composed error. International Economics Review, 18: 435-444.

Ministry of Agriculture and Rural Development (MoARD).2009. Agricultural Investment Potential of Ethiopia. Addis Ababa. Ethiopia.

MoFED.2006. Ethiopia: Building on Progress A Plan for Accelerated and Sustained Development to End Poverty (PASDEP) 2005/06-2009/10. Volume I, Addis Ababa, Ethiopia

MoFED (Ministry of Finance and Economic Development).2002. Ethiopia: Sustainable Development

MoFED. 2010. Growth and Transformation Plan (GTP) 2010/11-2014/15. Addis Ababa, Ethiopia.

Msuya EE, Hisano S, Nariv T.2008. Analysis of Technical Efficiency of Maize Farmers in Tanzania: The Globalization Era. Paper presented in the XII World Congress of Rural Sociology of the International Rural Sociology Association, 6-11 July, Goyang, Korea

Nandeeswara rao $\mathrm{p}$ and Bealutukela.2015.Analyzing productivity in maize production: the case of borichaworeda in sidama zone, southern ethiopia. international journal of recent scientific research vol. 6, issue, 10, pp. 69846989.

Sinafikeh Asrat, Getawork Getachew and Alemayehu Seyoum,2010. Trend and Determinants of Cereal Productivity: Econometrics Analysis of Nationally Representative Plot-level Data. International Food Policy 
Research Institute: Development Strategy and Governance Division Discussion Paper, June 2010, Addis Ababa, Ethiopia.

Sorsie Deme, Nicolette Matthews and Janus Henning,2015.Analysis of factors affecting technical efficiency of smallholder maize farmers in Ethiopia, Conference Paper.

Tefaye, W., \& Beshir, H. 2014. Determinants of Technical Efficiency in Maize Production: The Case of Smallholder Farmers in Dhidhessa District of Illuababora Zone, Ethiopia. Journal of Economics and Sustainable Development, 5(12), 274-284

Thiam A., B. E. Bravo-Ureta and T.E. Rivas.2001. Technical efficiency in developing country agriculture: A metaanalysis. J. Agricultural Economices, 25: 235-243.

Thomas, C \& Maurice, S. 2013. Managerial Economics: Foundations of Business Analysis and Strategy. The Mcgraw-Hill

Timmer, C.P.1971. Using a probabilistic frontier function to measure technical efficiency. J. Political Economics, 79: 776-794.

Tsedeke Abate \& Bekele Shiferaw \& Abebe Menkir \& DagneWegary \& Yilma Kebede\& Kindie Tesfaye \& Menale Kassie \& Gezahegn Bogale \& Berhanu Tadesse \& Tolera Keno,2015. Factors that transformed maize productivity in Ethiopia.

Tsegaye Yilma and Ernst Berg.2015. Technical Efficiency of Maize Production in Southwestern Ethiopia: a case of jimma zone.

World Bank. 2006. Ethiopia: Managing Water Resources to Maximise Sustainable Growth. The World Bank Agriculture and Rural Development Department Report. Washington DC. USA

Yilma, T., \& Berg, E.2001. Technical Efficiency of Maize Production in Southwestern Ethiopia: a case of Jimma zone. Proceeding of Deutscher Tropentag, 9-11.

Yu, B., and A. Nin-Pratt. 2014. Fertilizer adoption in Ethiopiae's cereal production. Journal of Development and Agricultural Economics, 6(7): 318-337. 